\title{
molecules
}

ISSN 1420-3049

www.mdpi.com/journal/molecules

Article

\section{Chitosan Based Heterogeneous Catalyses: Chitosan-Grafted-Poly(4-Vinylpyridne) as an Efficient Catalyst for Michael Additions and Alkylpyridazinyl Carbonitrile Oxidation}

\author{
Khaled D. Khalil ${ }^{1,2}$ and Hamad M. Al-Matar ${ }^{1, *}$ \\ 1 Chemistry Department, Faculty of Science, University of Kuwait, P.O. Box 5969, Safat 13060, \\ Kuwait \\ 2 Chemistry Department, Faculty of Science, Cairo University, Giza 12613, Egypt \\ * Author to whom correspondence should be addressed; E-Mail: h.almatar@ku.edu.kw; \\ Tel.: +965-2498-7559; Fax: +965-2481-6482.
}

Received: 10 April 2013; in revised form: 28 April 2013 / Accepted: 28 April 2013 /

Published: 8 May 2013

\begin{abstract}
Chitosan-grafted-poly(4-vinylpyridine) (Cs-PVP) copolymers could be synthesized under heterogeneous conditions in presence of a potassium persulfate and sodium sulfite redox system. The synthesized graft copolymer could be utilized effectively, in the form of beads, as an efficient catalyst for Michael additions of active methylenes to functionally substituted alkenes. Moreover, methyl moiety oxidation in methyl pyridazinyl carbonitriles by $\mathrm{H}_{2} \mathrm{O}_{2}$ in the presence of chitosan-g-polyvinyl pyridine-supported iron (III) complex, Cs-PVP/Fe, could be affected. A variety of pyrans, naphthopyrans, and thiopyrans could be synthesized efficiently in the presence of these graft copolymer beads by novel catalytic routes. These polymeric catalysts could be used instead of the old toxic commercial organic basic catalysts, piperidine or pyridine, and could be readily isolated from the reaction mixture and recycled several times without significant loss of catalytic activity.
\end{abstract}

Keywords: chitosan; chitosan-g-poly(4-vinylpyridine); graft copolymer; [chitosan-g-PVP]-supported iron (III) complex; Michael additions 


\section{Introduction}

Recently, biocatalysis and sustainable chemistry researchers are directed to develop new green methodologies that aim to reduce and prevent pollution at its source [1-3]. Biocatalysis is a promising technique based on the use of natural renewable biological materials, such as enzymes and polymers, that provide cleaner methodologies with high selectivity and energy-efficient operation under mild conditions in contrast to the traditional chemical catalysts [4,5]. Chitosan (2-acetamido-2-deoxy- $\beta$-Dglucose-(N-acetylglucosamine) is a partially deacetylated polymer of chitin and is usually prepared from chitin by reflux with a strong alkaline solution [6-8]. Some time ago, the utility of chitosan as an efficient eco-friendly basic biocatalyst for Michael additions was reported and it could already be shown that chitosan can catalyze the addition of bi-functional active methylenes to arylidenemalononitriles and enaminones [9-12]. This type of reaction, involving simple addition of active methylenes, phenols and naphthols to electron poor functionally substituted alkenes, is an efficient C-C bond forming reaction. Classically these additions have been effected in the presence of homogeneous basic catalysis [13-17]. Recently emphasis has been placed on adopting instead heterogeneous recyclable catalyses [12,18]. So far a diversity of such catalyses were employed $[19,20]$. Moreover, chitosan, a chiral polysaccharide, has been used as an efficient catalyst for enantioselective syntheses that result in the creation of asymmetric products with chiral center(s) [21-25]. Previously, while using chitosan [9,11], we suffered from some disadvantages of this catalyst namely, that it afforded low yields of products in many of the investigated reactions and it could not easily be recycled because of its high hygroscopicity, leading it to form gels. Herein, we successfully overcome the drawbacks of chitosan and enhance its catalytic activity via heterogeneous grafting with 4-vinyl-pyridine (VP) [26] (Scheme 1), thereby producing a basic, recyclable, eco-friendly biocatalyst that could be used efficiently in Michael additions, especially when a stronger basic catalyst than chitosan, is required. Also, the use of the chitosan-g-polyvinyl pyridine, Cs-PVP in the form of beads is usually required to increase the catalytic activity of the catalyst [18,27,28].

Scheme 1. Preparation of chitosan-g-PVP catalyst.
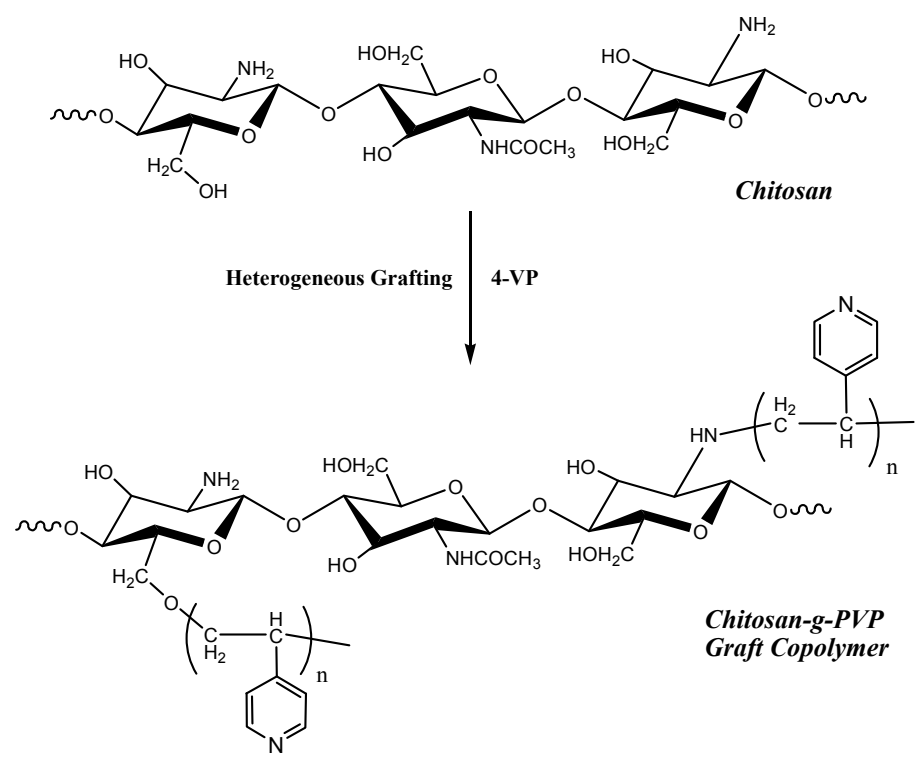
In addition, chitosan has been reported to have high affinity for adsorption of metal ions [29-32]. The adsorption capacity of $\mathrm{Fe}$ (III) ions for chitosan/4-vinylpyridine copolymer is higher than that of the original non-grafted chitosan owing to the presence of pyridine moieties in the PVP side chains [33]. Herein, chitosan-g-poly(4-vinylpyridine)-supported iron(III) complex, [Cs-PVP/Fe(III)], could be prepared in the form of beads (Scheme 2) [34] of higher catalytic activity, and effectively used as a powerful recyclable catalyst to oxidize methylpyridazinone in the presence of hydrogen peroxide to afford the corresponding furopyridazinone derivative. The surface adsorption of $\mathrm{Fe}^{3+}$ ions on the surface of chitosan involves nitrogen and oxygen atoms of the repeating units of chitosan as shown below [34]:

$$
\mathrm{Cs}-\mathrm{NH}_{2}+\mathrm{Fe}^{3+} \leftrightarrow\left[\mathrm{Cs}-\mathrm{NH}_{2}---\mathrm{Fe}---\right]^{+3}
$$

Scheme 2. Probable structure of chelated complexes of chitosan with iron (III) ions.

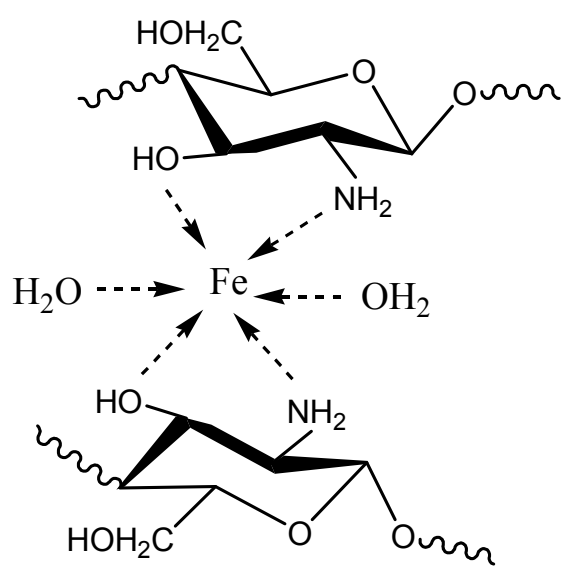

\section{Results and Discussion}

\subsection{Preparation of Cs-PVP Catalyst Beads}

The investigated basic catalyst, (Cs-PVP), was prepared through heterogeneous grafting of 4-vinylpyridine onto chitosan powder as previously reported by Khalil et al. [26]. The structure of grafted chitosan copolymer was confirmed by FT-IR, ${ }^{1} \mathrm{H}-\mathrm{NMR},{ }^{13} \mathrm{C}-\mathrm{NMR}$ and elemental analysis as reported in our previous work [26]. Elemental analysis showed that the nitrogen content of chitosan, $\mathrm{N} \%=7.1$, was increased upon grafting with 4-vinylpyridine to $\mathrm{N} \%=8.0$, which is an evidence for the presence of pyridine moieties. The structure of the grafted copolymer was confirmed by FTIR, that showed a characteristic $\mathrm{C}=\mathrm{N}$ groups band at $2,197 \mathrm{~cm}^{-1}$ from the poly 4-vinylpyridine chains (Figure 1). Also, the presence of pyridine rings is confirmed in the ${ }^{1} \mathrm{H}-\mathrm{NMR}$ spectrum (Figure 2) by the presence of the peaks at 7.1 and $8.5 \mathrm{ppm}$ in the aromatic range (Figure 2). 
Figure 1. FTIR of (a) Chitosan, (b) chitosan-g-poly(4-vinylpyridine) copolymer $80 \%$ G.

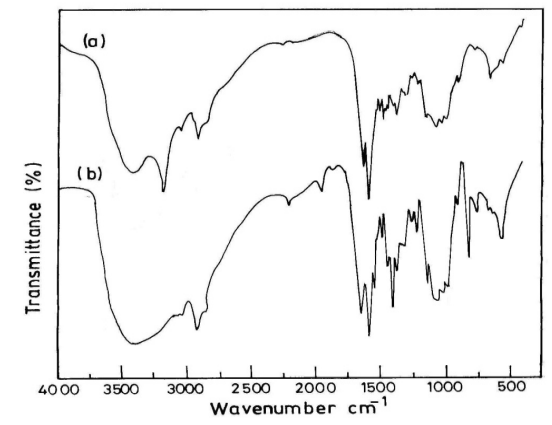

Figure 2. ${ }^{1} \mathrm{H}-\mathrm{NMR}$ spectrum of $80 \%$ VP grafted chitosan.

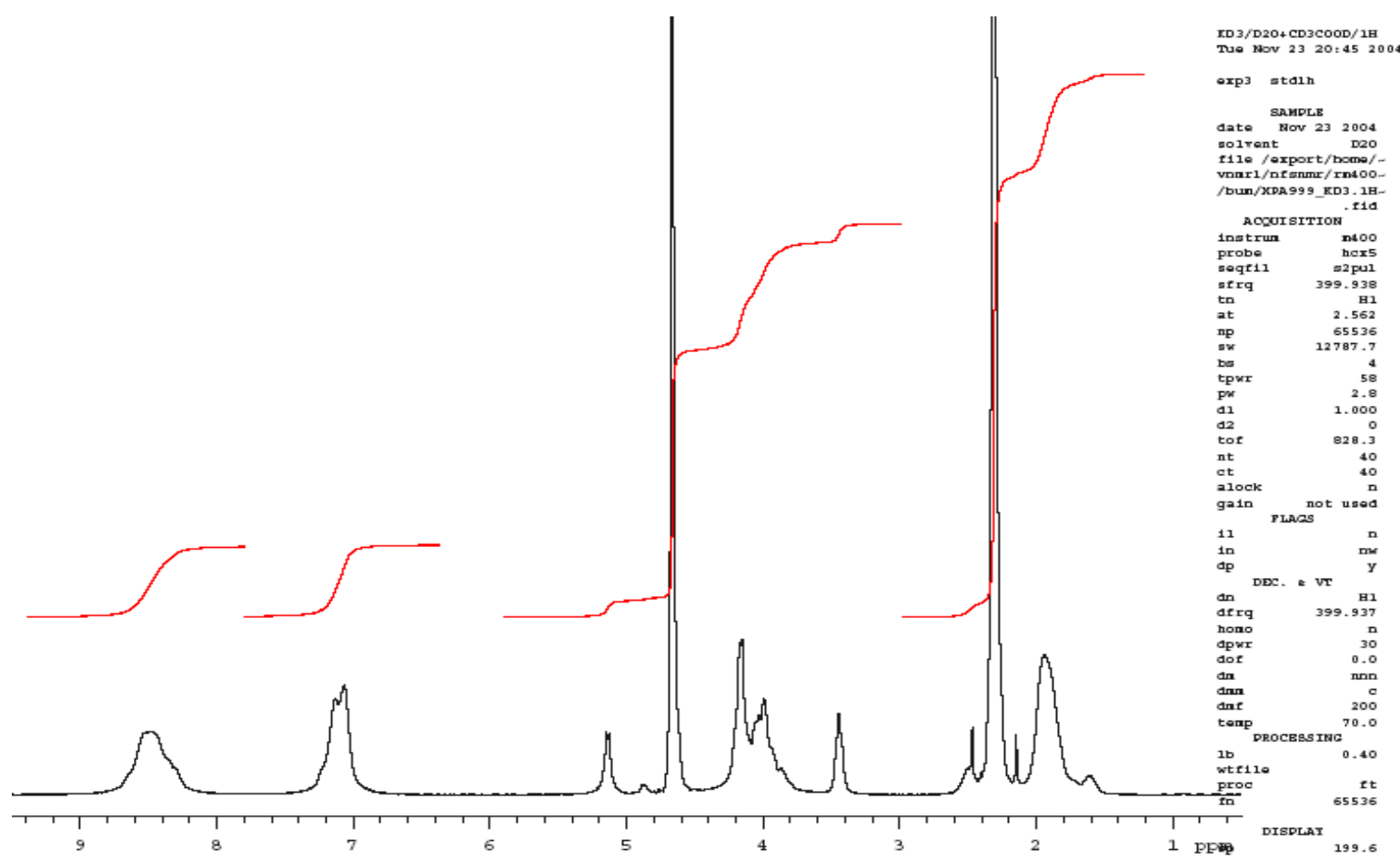

The prepared Cs-PVP beads exhibited more basic character (pka $=5.9)$, as compared to chitosan $(\mathrm{pka}=6.4)$, owing to the presence of pyridine moieties along the chitosan backbone. The cross-linked chitosan graft copolymer is characterized by higher thermal stability as compared to chitosan [26] so it could then be used effectively in higher temperature reactions (TGA was reported previously [26]).

\subsection{Applying Cs-PVP Beads as Efficient Basic Heterogeneous Catalyst in Michael Additions}

Benzylidene-malononitrile 1 reacted with dimedone to yield the chromene-3-carbonitrile derivative 2 in an excellent yield ( $>95 \%)$, more than that was obtained in presence of the original chitosan (75\%), (Scheme 3). The product structure was assigned by using X-ray crystallographic analysis (Figure 3) [35]. These derivatives could be previously prepared in the presence of homogeneous basic catalysts [9-17]. As a result of the cross-linking nature of the invented Cs-PVP catalyst, it could be readily isolated by simple filtration and reused again for more than five times without loss of its catalytic activity, after extensive washing with hot ethanol and drying in an oven at $100{ }^{\circ} \mathrm{C}$ for $4 \mathrm{~h}$. Similarly, reaction of 1 with cyclohexanone was conducted successfully in the presence of Cs-PVP beads to give a similar 
product 3 to that was obtained previously [9] in the presence of chitosan (55\%) but in much higher yield ( $\sim 90 \%)$. While the reaction of 1 with ethyl acetoacetate has been reported earlier [36] to produce the 2-aminopyran 4 together with the benzene derivative 5, only 4 was formed in a higher yield $\sim 90 \%$ when 1 was reacted with ethyl acetoacetate in ethanol in presence of Cs-PVP beads. Again, the produced structure was confirmed by X-ray crystal structure determination (Figure 4). The catalyst could be easily isolated from the reaction media and recycled several times after being washed with ethanol and dried in an oven. $\alpha$-Naphthol 6 also reacted with 1 to yield 7 in $86 \%$ yield.

Scheme 3. Heterogeneous basic catalyzed Michael additions using Cs-PVP beads.

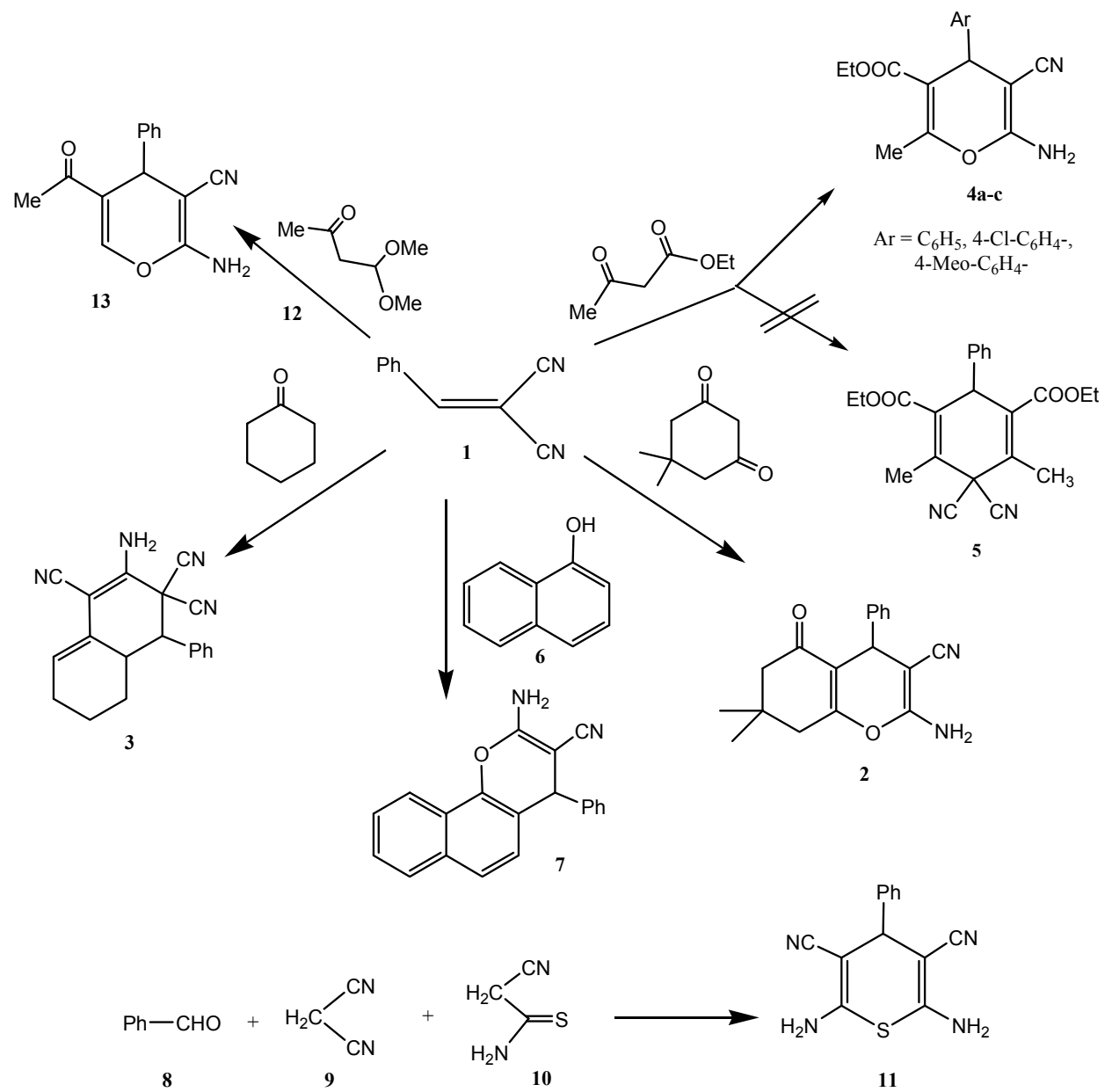

Figure 3. X-ray crystal structure of chromene-3-carbonitrile derivative 2.

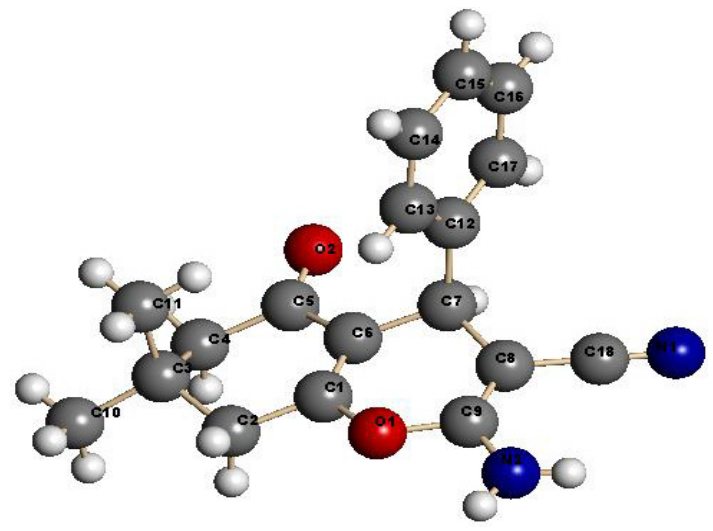


Figure 4. X-ray crystal structure of 2-aminopyran derivative 4.

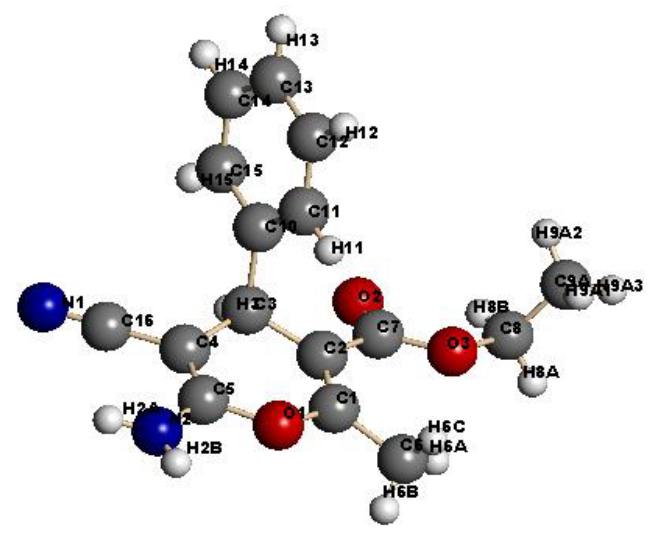

In order to estimate the appropriate catalyst loading, a model reaction of benzylidene-malononitrile $1(1.54 \mathrm{~g}, 10 \mathrm{mmol})$ and dimedone $(1.40 \mathrm{~g}, 10 \mathrm{mmol})$ was carried out in $25 \mathrm{~mL}$ absolute ethanol using $1,5,10,15$, and $20 \% \mathrm{wt}$. of catalyst under the same conditions. The $10 \%$ wt catalyst loading was found to be the optimal quantity (Figure 5). Catalyst was reused four times and the results showed that the chitosan graft copolymer can be reused as such without significant loss in its catalytic activity (Table 1).

Figure 5. Optimization of the chitosan graft copolymer as basic catalyst.

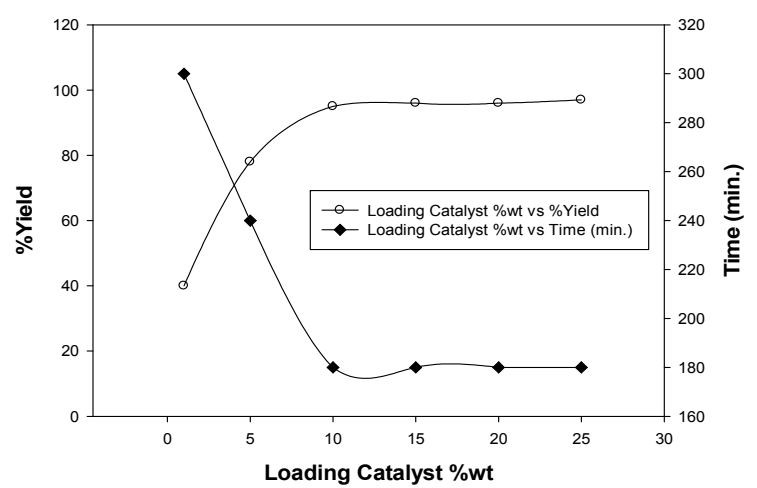

Table 1. Recyclability of the chitosan graft copolymer as basic catalyst.

\begin{tabular}{cccccc}
\hline Product & Fresh Catalyst & Recycled (1) & Recycled (2) & Recycled (3) & Recycled (4) \\
\hline $\mathbf{2}$ & 95 & 93 & 93 & 92 & 92 \\
\hline
\end{tabular}

All these products were previously $[9,11]$ obtained in presence of chitosan but in lower yields, and furthermore, with the latter, removal of the product from the catalyst could not be easily accomplished as in each case the catalyst adsorbed part of the reaction media forming a gel mass. The cross-linked graft copolymer beads did not behave similarly and its use in the form of beads has enhanced its catalytic activity to a great extent. The thiopyran $\mathbf{1 1}$ could be obtained in a one pot reaction of $\mathbf{8}, \mathbf{9}$, and $\mathbf{1 0}$, (yields: $\mathrm{Cs}=80 \%$; Cs-PVP $=95 \%$; cf. Scheme 3). This product has been obtained earlier via addition of cyanothioacetamide to $\mathbf{1}$. While $\mathbf{1}$ failed to add to $\mathbf{1 2}$ in the presence of chitosan or even piperidine, it reacted smoothly with $\mathbf{1 2}$ in the presence of Cs-PVP beads affording the 5-acetyl-2-aminopyran derivative $\mathbf{1 3}$ in $80 \%$ yield. 
Some time ago the formation of dieneamide 15a via reaction of enaminone 14a with malononitrile has been reported from our laboratories [37,38]. We have recently shown that this product can be obtained in better yields by utilizing chitosan as catalyst [11]. Now we report that the dieneamide 15a is also obtainable in higher yield in the presence of grafted chitosan Cs-PVP beads (yields: Cs $=80$; Cs-PVP $=90$ ). Moreover, the furanyl derivative $\mathbf{1 5 b}$ could be obtained from $\mathbf{1 4 b}$ (yields: Cs $=78$; Cs-PVP = 95). The postulated mechanism of this remarkable transformation is shown below (Scheme 4).

Scheme 4. Synthesis of dieneamides by using Cs-PVP basic catalyst.

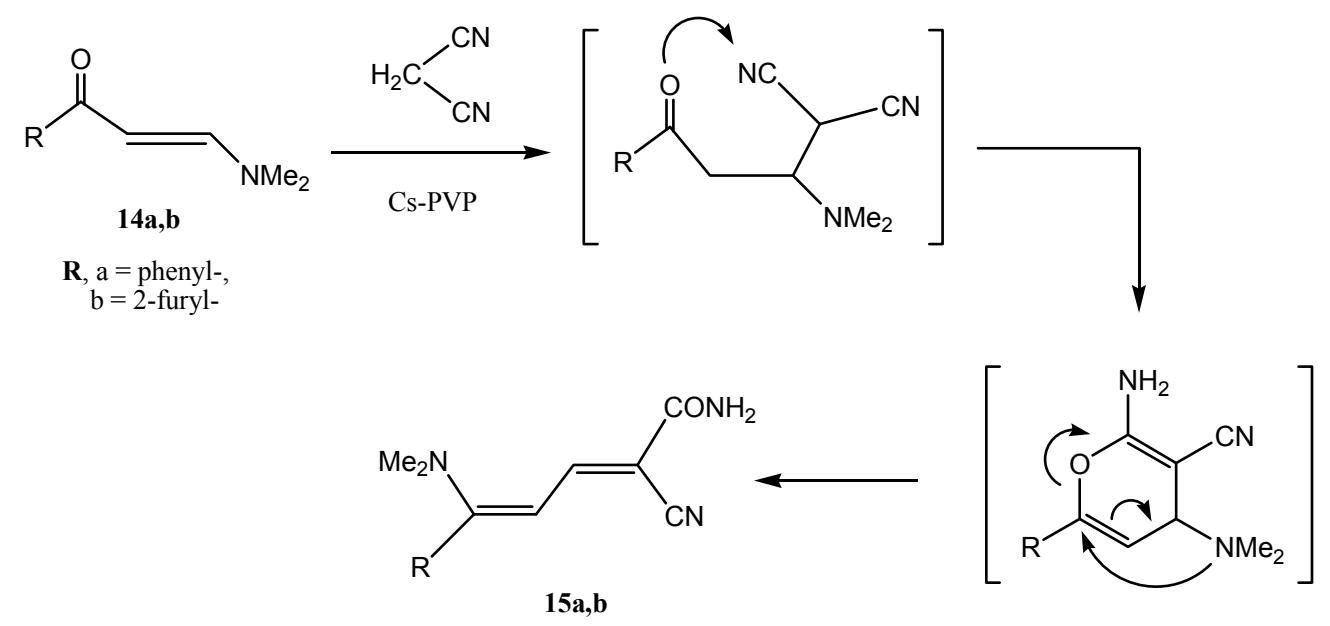

\subsection{Preparation of Cs-PVP/Fe(III) Catalyst Beads}

The second goal of our study was the formation of chitosan-PVP/Fe(III) complex, Cs-PVP/Fe(III), using same methodology that published by Ngah et al. [33] and Burke et al. [34]. It is of value to mention that the previously prepared basic catalyst Cs-PVP exhibited higher metal-binding capacity, as compared to the original chitosan, owing to the presence of extra binding nitrogen-atoms with free lone pairs like in $\mathrm{NH}_{2}$ groups and pyridine moieties. When $50 \mathrm{mg}$ of chitosan or graft chitosan were placed in a $10 \mathrm{nM} \mathrm{Fe}^{3+}$ solution at $\mathrm{pH}=1.8$, for a period of time $5 \mathrm{~h}$, it was found that the adsorption capacity of the graft copolymer, Cs-PVP, was higher than that of the original chitosan, since the amount of adsorbed iron on the graft copolymer was $0.086 \mathrm{mmol} \mathrm{Fe} / \mathrm{g}$ while it was 0.077 is for original chitosan. Elemental analysis of Fe(III)-supported chitosan graft copolymer by EDS (Table 2, Figure 6) showed that $32 \%$ of Fe(III) wascon the surface as result of the metal complexation with the $\mathrm{N}$-atoms of glucosamine units and pyridine moieties and C-6 hydroxyl group binding sites over the chitosan graft surface.

Table 2 EDS of chitosan- $g$-poly(4-vinylpyridine) $/ \mathrm{Fe}^{3+}$ chelate.

\begin{tabular}{ccc}
\hline Element & Weight\% & Atomic\% \\
\hline C K & 17.24 & 38.89 \\
N K & 4.25 & 8.22 \\
O K & 12.25 & 20.74 \\
Fe K & 66.27 & 32.15 \\
Totals & 100.00 & \\
\hline
\end{tabular}


Figure 6. EDS of $\mathrm{Fe}(\mathrm{III})$ supported chitosan-poly(4-vinylpyridine) graft, $\mathrm{Cs}-\mathrm{PVP} / \mathrm{Fe}^{3+}$ complex.

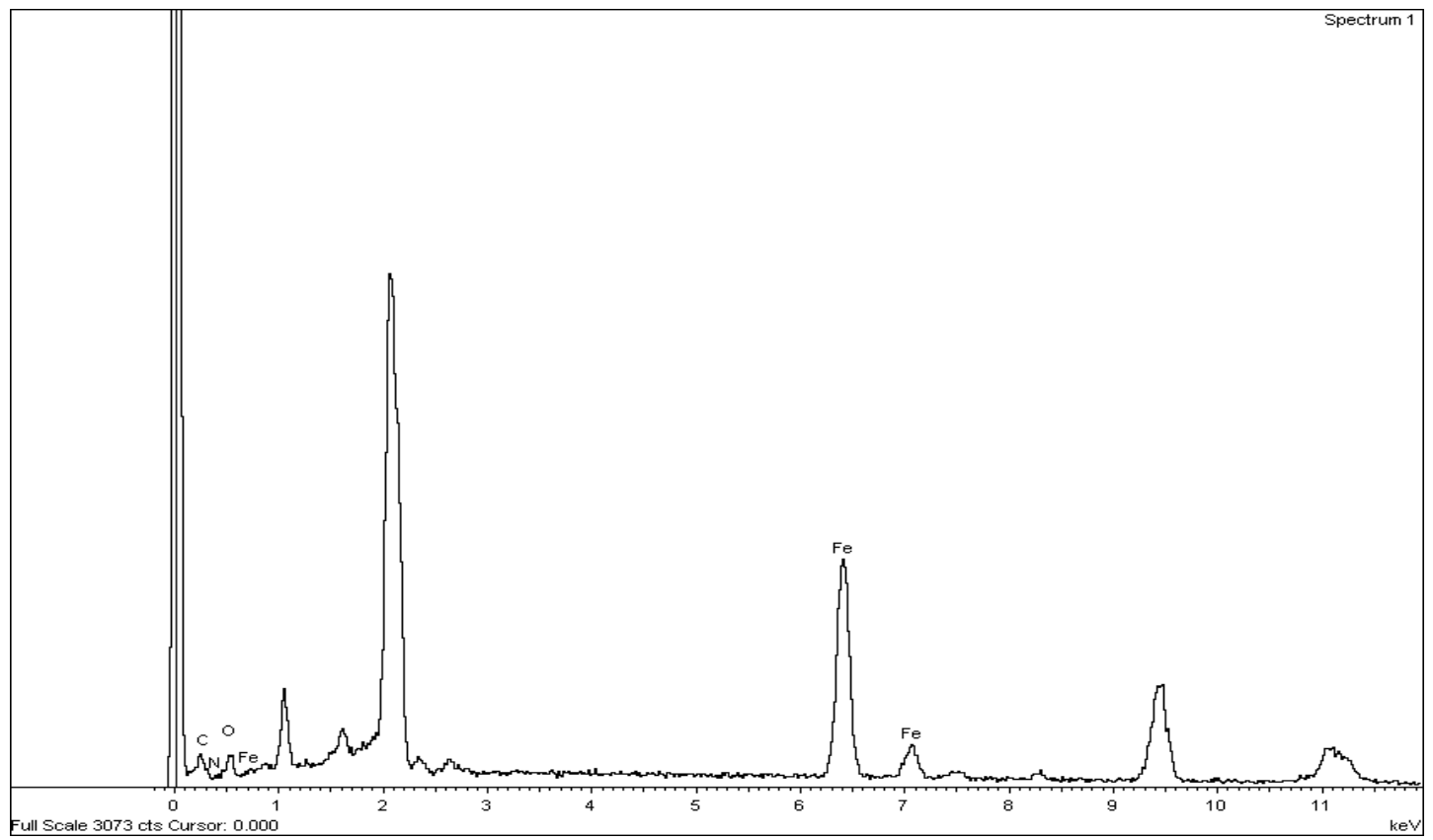

The produced Cs-PVP/F(III) complex could be used successfully as an efficient catalyst for oxidation of methyl pyridazinones as shown in the last part of our study. Scanning electron microscopy exhibited great differences in the surface morphology upon grafting and complexation with $\mathrm{Fe}^{3+}$ ions (Figure 7). From the SEM the fibrous nature of chitosan is lost upon grafting and regular geometric shapes appeared that were attributed to the coordination with $\mathrm{Fe}^{3+}$ ions. The suggested structure of chitosan Fe(III) chelates is supposed [39] to occur as follows (Scheme 4).

Figure 7 Scanning electron microscope for (a) Chitosan Cs, (b) Cs-PVP 80\%G, (c) $\mathrm{Cs}-\mathrm{PVP} / \mathrm{Fe}^{3+}$ complex.

(a)

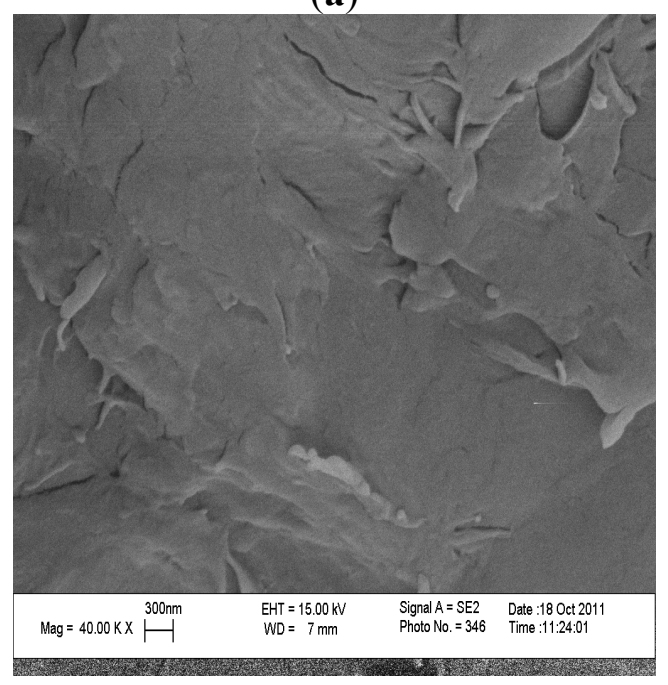

(b)

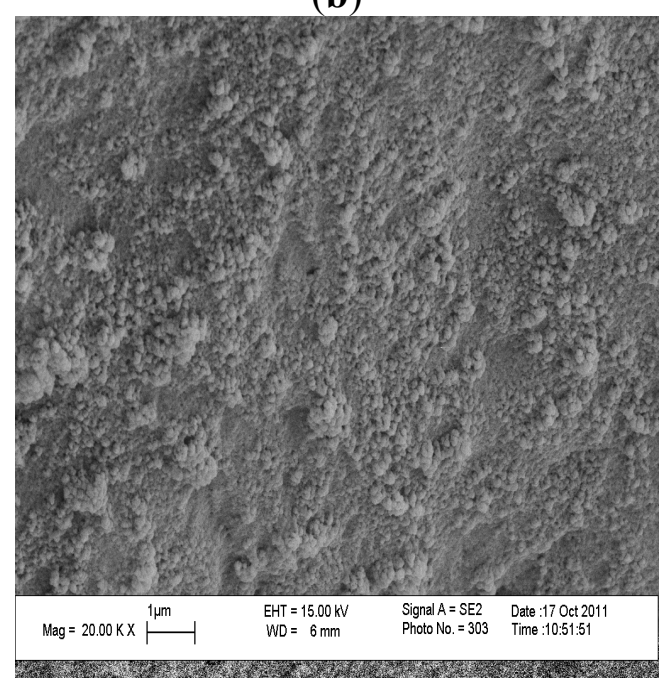


Figure 7. Cont.

(c)

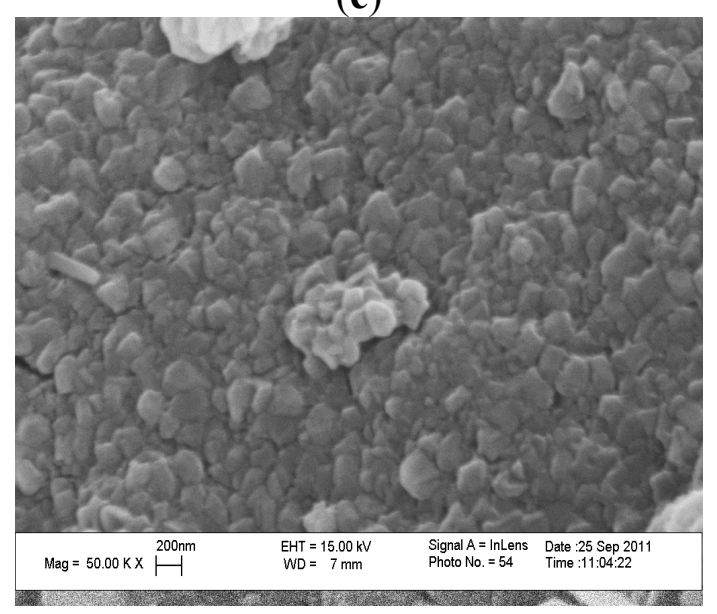

\subsection{Utility of Cs-PVP/Fe(III) beads as an Efficient Catalyst for Oxidation of Methyl Pyridazinones}

One of the major challenges for organic synthesis is how to effect controlled oxidation of nonactivated alkyl functions. Several approaches exist among which Fe (III) Chitosan-PVP copolymer catalysts are of utility. We would like here to report first successful controlled oxidation of the methyl function in 16 utilizing Cs-PVP/Fe (III) chelates. Thus refluxing 16a,b with Cs-PVP/Fe (III) complex in the presence of excess hydrogen peroxide afforded 17a,b. The potential utility of $\mathbf{1 7} \mathbf{a}, \mathbf{b}$ as precursors to phthalazines via addition of electron poor alkenes, thus replacing thienopyridazines classically utilized by Elnagdi et al. for this purpose will be subject of further communication (Scheme 5).

Scheme 5. Selective oxidation of methylpyridazinones in presence of chitosan-based iron (III) catalyst, Cs-PVP/Fe(III).<smiles>Cc1cnn(C2CCCCC2)c(=O)c1C#N</smiles>

$16 \mathbf{a}, \mathbf{b}$

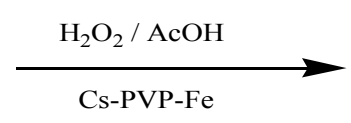

$\operatorname{Ar}=$ phenyl, $p$-Chlorophenyl

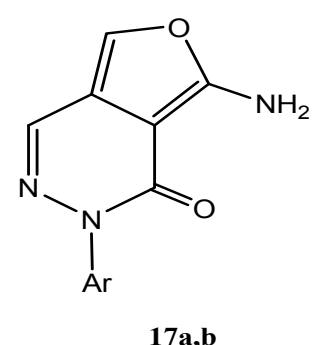

$17 \mathbf{a}, \mathbf{b}$

\section{Experimental}

\subsection{General}

Melting points were recorded on Gallenkamp apparatus and are reported uncorrected. The Fourier Transform infrared (FTIR) spectra were recorded in KBr pellets on a JASCO FT-IR-6300 system at a resolution of $4 \mathrm{~cm}^{-1}$ in the $400-4000 \mathrm{~cm}^{-1}$ range. ${ }^{1} \mathrm{H}-\mathrm{NMR}$ measurements were determined on a Bruker DPX spectrometer, at $400 \mathrm{MHz}$ for ${ }^{1} \mathrm{H}-\mathrm{NMR}$ and $100 \mathrm{MHz}$ for ${ }^{13} \mathrm{C}-\mathrm{NMR}$, in DMSO- $\mathrm{d}_{6}$ as solvent using TMS as internal standard. Solid NMR spectra were recorded on a $600 \mathrm{MHz}$ Bruker Avance II 
spectrometer, operating at $150 \mathrm{MHz}$ for ${ }^{13} \mathrm{C}-\mathrm{NMR}$. Mass spectra were measured on a GC-MS DFS-Thermo spectrometer, using $70 \mathrm{eV}$ EI. Elemental analyses were measured by means of an Elementar-Vario Microcube Elemental Analyzer. The scanning electron microscopy (SEM) was conducted using a JEOL JSM-630 J scanning electron microscope operated at $20 \mathrm{kV}$. (TGA data was reported previously [26]) Single crystal X-ray crystallographic analysis was performed using a Rigaku Rapid II instrument. Copies of original data can be provided upon request.

\subsection{Samples}

Chitosan, with degree of deacetylation $(\mathrm{DDA})=77.8 \%$, was kindly supplied by Professor Furuhata of Tokyo Institute of Technology (T. I. Tech.). 4-Vinylpyridine, initiators $\left(\mathrm{K}_{2} \mathrm{~S}_{2} \mathrm{O}_{7}\right.$ and $\left.\mathrm{NaHSO}_{3}\right)$, and all solvents were purchased from Sigma-Aldrich Chemicals (Germany) and used without any further purification.

\subsection{Materials}

\subsubsection{Preparation of Chitosan Beads Cs}

Chitosan beads were prepared according to the published procedure of Ngah et al. [30]. Chitosan solution was prepared by dissolving chitosan powder $(2.00 \mathrm{~g})$ in $5 \%(\mathrm{v} / \mathrm{v})$ acetic acid solution $(60 \mathrm{~mL})$. The chitosan solution was sprayed into $0.50 \mathrm{M} \mathrm{NaOH}$ solution $(500 \mathrm{~mL})$ as a precipitation bath, which neutralized the acetic acid within the chitosan gel and thereby coagulated the chitosan gel as uniform spherical chitosan gel beads. A magnetic stirrer was used to stir the aqueous $\mathrm{NaOH}$ solution. The wet chitosan gel beads (hereafter called chitosan beads) were extensively rinsed with distilled water to remove any $\mathrm{NaOH}$, filtered and finally air-dried to remove the water from the pores of the structure. The beads were then stored in distilled water and ready for use.

\subsubsection{Preparation of Basic Catalyst Chitosan-g-poly(vinylpyridine)(Cs-PVP) Beads}

\subsubsection{Heterogeneous Grafting of 4-Vinylpyridine onto Chitosan}

The grafting of 4-vinylpyridine onto chitosan was conducted using the same procedure reported in the literature [21], a typical heterogeneous method in which chitosan powder (1.00 g) was suspended in distilled water $(50 \mathrm{~mL})$ and mixed with $3 \times 10^{-3} \mathrm{M}$ of redox initiator mixture (1:0.75) $\mathrm{K}_{2} \mathrm{~S}_{2} \mathrm{O}_{7}$ and $\mathrm{NaHSO}_{3}$, respectively. 4-Vinylpyridine monomer (1.05 g, $\left.10 \mathrm{mmol}\right)$ was added and the reaction was conducted at $55{ }^{\circ} \mathrm{C}$ for $3 \mathrm{~h}$. At the end of reaction time, the graft copolymer was filtered off and washed with water and was then extensively purified with hot ethanol using the Soxhlet extraction technique to get rid of the unreacted monomer. Finally the graft copolymer (Cs-PVP), was dried. An $80 \%$ graft was obtained. The used amount in all reaction was $10 \%$ wt of the Cs-PVP catalyst.

\subsubsection{Preparation of Chitosan/PVP Copolymer Beads}

Applying the same reported methodology [30], freshly prepared Cs-PVP copolymer was converted into spherical beads by dissolving graft copolymer $(1.00 \mathrm{~g})$ in $5 \%(\mathrm{v} / \mathrm{v})$ acetic acid solution $(50 \mathrm{~mL})$. 
The graft copolymer solution was treated as usual and thereby the gel beads were coagulated. The wet grafted chitosan beads were extensively washed with distilled water to be ready for use.

3.3.3. Preparation of Cs-PVP-Supported Iron(III) Complex by Adsorption of $\mathrm{Fe}^{3+}$ Ions on Cs-PVP Grafted Chitosan Beads Using $\mathrm{Fe}\left(\mathrm{NO}_{3}\right)_{3}$ [34]

The degree of adsorption was calculated based on the difference of $\mathrm{Fe}^{3+}$ concentration in aqueous solution before and after adsorption at a wavelength of $248 \mathrm{~nm}$ using an atomic absorption spectrophotometer (Perkin-Elmer 3100 Model). For Fe(III) adsorption onto Cs-PVP, a contact time of $5 \mathrm{~h}$ at $\mathrm{pH} 1.8$ was used for stirred mixture of Cs-PVP beads $(0.05 \mathrm{~g})$ and Fe(III) solution $(100 \mathrm{~mL}$, $10 \mathrm{mM}$ ) in a $250 \mathrm{~mL}$ beaker. The amount adsorbed on the beads was calculated according to the following equation:

$$
\text { Adsorption Capacity }\left(q_{e}\right)=\frac{\left(\mathrm{C}_{0}-\mathrm{C}_{\mathrm{e}}\right) \mathrm{V}}{\mathrm{W}}
$$

where $\mathrm{C}_{0}$ is the initial $\mathrm{Fe}(\mathrm{III})$ concentration (ppm), $\mathrm{C}_{\mathrm{e}}$ is the final concentration of $\mathrm{Fe}(\mathrm{III})$ after the adsorption time, $\mathrm{V}$ is the volume of $\mathrm{Fe}(\mathrm{III})$ solution $(\mathrm{mL})$ and $\mathrm{W}$ is the used weight of graft copolymer Cs-PVP beads ( $\mathrm{g}$ ). The yellowish-colored beads adsorbed $\mathrm{Fe}^{3+}$ were washed thoroughly with distilled water and stored in distilled water for further use. Under the previous conditions, the maximum adsorption capacity was obtained as $0.089 \mathrm{mmol} \mathrm{Fe}^{3+} / \mathrm{g}$ chitosan.

\subsubsection{Reaction of Benzylidene-Malononitrile 1 with Dimedone and Cyclohexanone}

A mixture of benzylidene-malononitrile 1 (1.54 g, $10.0 \mathrm{mmol})$ with either dimedone or cyclohexanone $(10.0 \mathrm{mmol})$ in absolute ethanol $(50 \mathrm{~mL})$ was refluxed for $3 \mathrm{~h}$ in the presence of a catalytic amount (10\%wt.) of the catalyst (Method A using Cs beads and Method B using Cs-PVP beads). The solid product, so formed, was filtered of and recrystallized from ethanol.

2-Amino-7,7-dimethyl-5-oxo-4-phenyl-5,6,7,8-tetrahydro-4H-chromene-3-carbonitrile (2). Colorless crystals; \% Yields: Method A (Cs beads $=75 \%)$, Method B (Cs-PVP beads $=95 \%)$; Mp $234{ }^{\circ} \mathrm{C}$, lit. 233-235 ${ }^{\circ} \mathrm{C}$ [40]; IR (KBr): $v=1708(\mathrm{C}=\mathrm{O}), 2198(\mathrm{CN}), 3341,3420\left(\mathrm{NH}_{2}\right) \mathrm{cm}^{-1} ;{ }^{1} \mathrm{H}-\mathrm{NMR}$ $\left(\mathrm{DMSO}_{6}\right): \delta=0.96\left(\mathrm{~s}, 3 \mathrm{H}, \mathrm{CH}_{3}\right), 1.05\left(\mathrm{~s}, 3 \mathrm{H}, \mathrm{CH}_{3}\right), 2.09-2.24\left(\mathrm{~s}, 2 \mathrm{H}, \mathrm{CH}_{2}\right), 2.47\left(\mathrm{~s}, 2 \mathrm{H}, \mathrm{CH}_{2}\right), 4.20$ (s, 1H, CH, C-4 pyran), 7.01 (s, 2H, NH ), 7.15-7.28 (m, 5H, phenyl-H); ${ }^{13} \mathrm{C}-\mathrm{NMR}$ (DMSO-d 6 ): $\delta=26.9\left(\mathrm{CH}_{3}\right), 28.5\left(\mathrm{CH}_{3}\right), 31.9\left(\mathrm{C}_{\left.\left(\mathrm{CH}_{3}\right)_{2}\right),} 35.7(\mathrm{C}-4\right.$, pyran $), 50.1\left(\mathrm{CH}_{2}\right), 58.5\left(\mathrm{CH}_{2}\right), 119.8(\mathrm{CN})$, 112.9, 126.7, 127.3, 128.5, 144.8, 158.6, 162.7 (aromatic carbons); $\mathrm{MS}, \mathrm{m} / z(\%), 294.1\left(\mathrm{M}^{+}, 29\right), 217.1$ (66), 55.1 (100). Anal. Calcd. for $\mathrm{C}_{18} \mathrm{H}_{18} \mathrm{~N}_{2} \mathrm{O}_{2}$ : C, 73.45; H, 6.16; N, 9.52. Found: C, 73.36; H, 6.10; $\mathrm{N}, 16.43$.

2-Amino-4-phenyl-4a,5,6,7-tetrahydronaphthalene-1,3,3(4H)-tricarbonitrile (3). Yellow crystals; \% Yields: Method A (Cs beads $=55 \%)$, Method B (Cs-PVP beads $=90 \%)$; Mp $252{ }^{\circ} \mathrm{C}$; Lit. Mp $253{ }^{\circ} \mathrm{C}[9]$; IR (KBr): $v=1650$ (olefinic $\mathrm{C}=\mathrm{C}), 2211(\mathrm{CN}), 2254(\mathrm{CN}) 3341,3420\left(\mathrm{NH}_{2}\right) \mathrm{cm}^{-1}$; ${ }^{1} \mathrm{H}-\mathrm{NMR}$ $\left(\right.$ DMSO-d $\left._{6}\right): \delta=0.84(\mathrm{~m}, 1 \mathrm{H}, 5-\mathrm{H}), 1.44(\mathrm{~m}, 2 \mathrm{H}, 5-\mathrm{H}, 6-\mathrm{H}), 1.66(\mathrm{~m}, 1 \mathrm{H}, 6-\mathrm{H}), 2.04(\mathrm{~m}, 1 \mathrm{H}, 7-\mathrm{H})$, 2.17 (m, 1H, 7-H), 2.80 (m, 1H, 4a-H), 3.52 (d, 3J = $12.3 \mathrm{~Hz}, 1 \mathrm{H}, 4-\mathrm{H}), 5.72$ ("s", 1H, 8-H), 7.37 
(s, 2H, NH ), 7.41 (m, 3H, m-H, $p$-H, Phenyl), 7.48 (m, 1H, o-H, Phenyl), 7.59 (m, 1H, $o-\mathrm{H}$, Phenyl); ${ }^{13} \mathrm{C}-\mathrm{NMR}$ (DMSO-d ${ }_{6}$ ): $\delta=21.0$ (C-6), 24.9 (C-7), 27.0 (C-5), 33.8 (C-4a), 42.9 (C-3), 50.5 (C-4), 81.5 (C-1), 112.4 (3-CN), 112.6 (3-CN), 116.2 (1-CN), 120.3 (C-8), 126.9 (o-C, Phenyl), 128.6 (m-C, Phenyl), 128.8 (C-8a), 128.9 (p-C, Phenyl), 132.4 (o-C, Phenyl), 134.6 ( $i$-C, Phenyl), 143.6 (C-2); MS, $m / z(\%), 300.2\left(\mathrm{M}^{+}, 100\right), 209.1$ (43), $91.1(54)$.

\subsubsection{Reaction of Arylidene-Malononitrile with Ethyl Acetoacetate}

A mixture of the arylidenemalononitrile derivative (phenyl, $p$-chlorophenyl or $p$-methoxyphenyl) $(10.0 \mathrm{mmol})$ with ethyl acetoacetate $(10.0 \mathrm{mmol})$ in absolute ethanol $(50 \mathrm{~mL})$ was refluxed for $3 \mathrm{~h}$ in the presence of catalytic amount (10\%wt.) of the catalyst (Method A using Cs beads and Method B using Cs-PVP beads). The solid product, so formed, was filtered off and recrystallized from ethanol.

Ethyl 6-amino-5-cyano-2-methyl-4-phenyl-4H-pyran-3-carboxylate (4a). Colorless crystals; \% Yields: Method A (Cs beads = 59\%), Method B (Cs-PVP = 90\%); Mp $194{ }^{\circ} \mathrm{C}$; Lit. Mp 194-195 ${ }^{\circ} \mathrm{C}$ [41]; IR $(\mathrm{KBr}): v=1691(\mathrm{C}=\mathrm{O}), 2190(\mathrm{CN}), 3329,3385\left(\mathrm{NH}_{2}\right) \mathrm{cm}^{-1} ;{ }^{1} \mathrm{H}-\mathrm{NMR}\left(\mathrm{DMSO}_{6}\right): \delta=1.03$ (t, $J=7.0 \mathrm{~Hz}, 3 \mathrm{H}$, ester $\left.\mathrm{CH}_{3}\right), 2.32\left(\mathrm{~s}, 3 \mathrm{H}\right.$, pyran- $\left.\mathrm{CH}_{3}\right), 3.98\left(\mathrm{AB}\right.$ of $\left.\mathrm{ABX}_{3}, J=7.0 \mathrm{~Hz}, 2 \mathrm{H}, \mathrm{OCH}_{2}\right)$, 4.32 (s, 1H, H-4), 6.93 (br. s, 2H, NH 2 ), 7.16-7.34 (m, 5H, Phenyl); ${ }^{13} \mathrm{C}-\mathrm{NMR}$ (DMSO-d 6 ): $\delta=13.7$ $\left(\mathrm{CH}_{3}\right.$, ester), $18.1\left(\mathrm{CH}_{3}\right), 38.8(\mathrm{C}-4), 57.3(\mathrm{C}-3), 60.1\left(\mathrm{CH}_{2}\right.$, ester), $107.3(\mathrm{C}-5), 119.6(\mathrm{CN}), 126.8$ (C-4', Phenyl), 127.1 (C-2', Phenyl), 128.4 (C-3', Phenyl), 144.8 (C-1', Phenyl), 156.5 (C-6), 158.5 (C-2), $165.4(\mathrm{C}=\mathrm{O})$; MS, $m / z(\%), 284.1\left(\mathrm{M}^{+}, 70\right), 207.1$ (100). Anal. Calcd. for $\mathrm{C}_{16} \mathrm{H}_{16} \mathrm{~N}_{2} \mathrm{O}_{3}$ : C, 67.59; H, 5.67; N, 9.85. Found: C, 67.44; H, 5.61; N, 9.70.

Ethyl 6-amino-4-(4-chlorophenyl)-5-cyano-2-methyl-4H-pyran-3-carboxylate (4b). Pale yellow crystals; \% Yields: Method A (Cs beads $=68 \%)$, Method B (Cs-PVP $=87 \%)$; $\mathrm{Mp} 162{ }^{\circ} \mathrm{C}$; IR $(\mathrm{KBr})$ : $v=1695(\mathrm{C}=\mathrm{O}), 2210(\mathrm{CN}), 3330,3400\left(\mathrm{NH}_{2}\right) \mathrm{cm}^{-1} ;{ }^{1} \mathrm{H}-\mathrm{NMR}\left(\mathrm{DMSO}-\mathrm{d}_{6}\right): \delta=1.10(\mathrm{t}, J=7.1 \mathrm{~Hz})$, $3 \mathrm{H}$, ester $\left.\mathrm{CH}_{3}\right), 2.39$ (s, 3H, pyran- $\left.\mathrm{CH}_{3}\right), 4.14\left(\mathrm{AB}\right.$ of $\left.\left.\mathrm{ABX}_{3}, J=7.1 \mathrm{~Hz}\right), 2 \mathrm{H}, \mathrm{OCH}_{2}\right), 4.34(\mathrm{~s}, 1 \mathrm{H}$, 4-H), 7.01 (br. s, 2H, NH2), 7.08 (d, 2H, $o-\mathrm{H}, J=8 \mathrm{~Hz}$, aryl), 7.37 (d, 2H, $m-\mathrm{H}, J=8 \mathrm{~Hz}$, aryl); ${ }^{13} \mathrm{C}-\mathrm{NMR}\left(\mathrm{DMSO}-\mathrm{d}_{6}\right): \delta=14.1\left(\mathrm{CH}_{3}\right.$ of $\left.\mathrm{CO}_{2} \mathrm{C}_{2} \mathrm{H}_{5}\right), 19.2\left(\mathrm{CH}_{3}\right), 37.0(\mathrm{C}-4), 56.1(\mathrm{C}-5), 61.3\left(\mathrm{O}-\mathrm{CH}_{2}\right)$, 106.5 (C-3), $118.6(\mathrm{CN}), 125.8,128.7,129.6,146.4,154.2,156.8$ (C-2, C-6), $167.0(\mathrm{C}=\mathrm{O})$; MS, $\mathrm{m} / \mathrm{z}$ (\%), $318.1\left(\mathrm{M}^{+}, 37\right), 207.1$ (100). Anal. Calcd. for $\mathrm{C}_{16} \mathrm{H}_{15} \mathrm{ClN}_{2} \mathrm{O}_{3}: \mathrm{C}, 60.29 ; \mathrm{H}, 4.74 ; \mathrm{Cl}, 11.12 ; \mathrm{N}$, 8.79. Found: C, 60.13; H, 4.66; Cl, 10.94; N, 8.57.

Ethyl 6-amino-5-cyano-4-(4-methoxyphenyl)-2-methyl-4H-pyran-3-carboxylate (4c). Colorless crystals; \% Yields: Method A (Cs beads $=70 \%)$, Method B (Cs-PVP =90\%); Mp. $145{ }^{\circ} \mathrm{C} ; \mathrm{Mp}$ 144-145 ${ }^{\circ} \mathrm{C}$ [41]; IR (KBr): $v=1684(\mathrm{C}=\mathrm{O}), 2188(\mathrm{CN}), 3325,3395\left(\mathrm{NH}_{2}\right) \mathrm{cm}^{-1} ;{ }^{1} \mathrm{H}-\mathrm{NMR}$ $\left.(\text { DMSO-d })_{6}\right): \delta=1.12\left(\mathrm{t}, J=7.1 \mathrm{~Hz}, 3 \mathrm{H}\right.$, ester $\left.\mathrm{CH}_{3}\right), 2.36\left(\mathrm{~s}, 3 \mathrm{H}\right.$, pyran- $\left.\mathrm{CH}_{3}\right), 3.79\left(\mathrm{~s}, 3 \mathrm{H}, \mathrm{O}-\mathrm{CH}_{3}\right)$, $3.99\left(\mathrm{AB}\right.$ of $\mathrm{ABX}_{3}, J=7.1 \mathrm{~Hz}, 2 \mathrm{H}$, ester $\left.\mathrm{CH}_{2}\right), 4.38$ (s, 1H, H-4), 4.54 (br. s, $\left.2 \mathrm{H}, \mathrm{NH}_{2}\right), 6.85(\mathrm{~d}, 2 \mathrm{H}$, H-3', $J=8 \mathrm{~Hz}$, aryl), 7.16 (d, 2H, H-2', $J=8 \mathrm{~Hz}$, aryl); ${ }^{13} \mathrm{C}-\mathrm{NMR}$ (DMSO-d 6 ): $\delta=18.1\left(\mathrm{CH}_{3}\right.$ of ester), $37.7(\mathrm{C}-4), 55.0\left(\mathrm{O}-\mathrm{CH}_{3}\right), 60.3\left(\mathrm{CH}_{2}\right.$ of ester), $62.4(\mathrm{C}-3), 108.1(\mathrm{C}-5), 114.1\left(\mathrm{C}-3{ }^{\prime}\right), 118.8(\mathrm{CN}), 128.7$ (C-2'), 136.0 (C-1'), 156.4 (C-4'), 157.4 (C-6), 158.5 (C-2), 160.3 (C=O); MS, $m / z(\%), 314.1$ (M $\left.{ }^{+}, 9\right)$, 184.1 (100). Anal. Calcd. for $\mathrm{C}_{17} \mathrm{H}_{18} \mathrm{~N}_{2} \mathrm{O}_{4}$ : C, 64.96; H, 5.77; N, 8.91. Found: C, 64.58; H, 5.62; N, 8.78. 


\subsubsection{Reaction of $\mathbf{1}$ with $\alpha$-Naphthol}

A mixture of benzylidene-malononitrile $1(1.54 \mathrm{~g}, 10.0 \mathrm{mmol})$ with $\alpha$-naphthol $(10.0 \mathrm{mmol})$ in absolute ethanol $(50 \mathrm{~mL})$ was refluxed for $4 \mathrm{~h}$ in the presence of a catalytic amount $(10 \% \mathrm{wt}$.) of the catalyst (Method A using Cs beads and Method B using Cs-PVP beads). The solid product, so formed, was filtered off and recrystallized from ethanol.

2-Amino-4-phenyl-4H-benzo[h]chromene-3-carbonitrile (7). This compound was obtained as yellow crystals [42]; \% Yields: Method A (Cs beads $=71 \%$ ), Method B (Cs-PVP $=86 \%)$; Mp $210{ }^{\circ} \mathrm{C}$; IR $(\mathrm{KBr}): \mathrm{v}=1605(\mathrm{Ar} \mathrm{C}=\mathrm{C}), 1656$ (olefinic $\mathrm{C}=\mathrm{C}), 2205(\mathrm{CN}), 3303,3448\left(\mathrm{NH}_{2}\right) \mathrm{cm}^{-1} ;{ }^{1} \mathrm{H}-\mathrm{NMR}$ $\left(\right.$ DMSO-d $\left._{6}\right): \delta=4.90(\mathrm{~s}, 1 \mathrm{H}, 4-\mathrm{H}), 7.11(\mathrm{~d}, 3 \mathrm{~J}=8.5 \mathrm{~Hz}, 1 \mathrm{H}, 5-\mathrm{H}), 7.56 \mathrm{~m}, 2 \mathrm{H} / 7.64, \mathrm{t}, 1 \mathrm{H} / 7.88, \mathrm{~d}$, 1H/8.27, d, $1 \mathrm{H}(6-\mathrm{H}, 7-\mathrm{H}, 8-\mathrm{H}, 9-\mathrm{H}, 10-\mathrm{H}), 7.18$ (s, 2H, NH ), 7.24 (m, 1H, p-H, Phenyl), 7.25 (m, 2H, $o$-H, Phenyl), 7.32 (m, 2H, $m$-H, Phenyl); ${ }^{13} \mathrm{C}-\mathrm{NMR}$ (DMSO-d ${ }_{6}$ ): $\delta=40.9(\mathrm{C}-4), 56.3(\mathrm{C}-3), 117.9$, 120.7, 122.7, 123.9, 126.2, 126.6, 126.7, 126.9, 127.6, 132.7 (C-4a, C-5, C-6, C-6a, C-7, C-8, C-9, C-10, C-10a, p-C, Phenyl), 120.4 (CN), 127.6 (o-C, Phenyl), 128.7 ( $m$-C, Phenyl), 142.7, 145.6 (C-10b, i-C, Phenyl), 160.1 (C-2); MS, $m / z(\%), 298.1\left(\mathrm{M}^{+}, 75\right), 221.1$ (100), 77 (10). Anal. Calcd. for $\mathrm{C}_{20} \mathrm{H}_{14} \mathrm{~N}_{2} \mathrm{O}$ : C, 80.52; H, 4.73; N, 9.39. Found: C, 80.19; H, 4.64; N, 8.17.

\subsubsection{One Pot Reaction of benzaldehyde and malononitrile with 2-cyanothioacetamide (11)}

A mixture of benzaldehyde (1.06 g, $10.0 \mathrm{mmol})$, malononitrile $(0.66 \mathrm{~g}, 10.0 \mathrm{mmol})$ and 2-cyanothioacetamide $(1.00 \mathrm{~g}, 10.0 \mathrm{mmol})$ in absolute ethanol $(50 \mathrm{~mL})$ was refluxed for $4 \mathrm{~h}$ in the presence of a catalytic amount (10\% wt.) of both catalysts (Method A using Cs beads and Method B using Cs-PVP beads). The solid product was filtered off and recrystallized from ethanol.

2,6-Diamino-4-phenyl-4H-thiopyran-3,5-dicarbonitrile (11). Yellow crystals; \% Yields: Method A (Cs

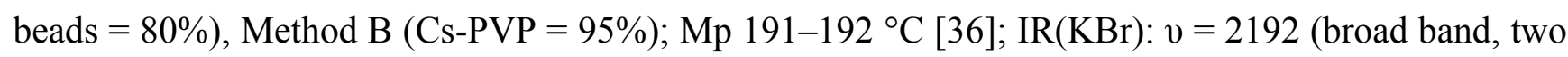
$\mathrm{CN}$ groups), 3300-3450 (two $\mathrm{NH}_{2}$ groups) $\mathrm{cm}^{-1}$; ${ }^{1} \mathrm{H}-\mathrm{NMR}$ (DMSO-d 6 ): $\delta=4.24(\mathrm{~s}, 1 \mathrm{H}, 4-\mathrm{H})$, 6.86-6.89 (s, 4H, two $\mathrm{NH}_{2}$ groups), 7.22-7.34 (m, 5H, Phenyl); ${ }^{13} \mathrm{C}-\mathrm{NMR}$ (DMSO-d $\mathrm{d}_{6}$ ): $\delta=43.4$ (C-4), 72.0 (C-3), 118.6 (two CN), 126.7, 127.2, 128.9, 143.2 (Phenyl), 151.0 (C-2, thiopyran); MS, $m / z$ (\%), $254.1\left(\mathrm{M}^{+}, 12\right), 228.1$ (41), 77.1 (100). Anal. Calcd. for $\mathrm{C}_{13} \mathrm{H}_{10} \mathrm{~N}_{4} \mathrm{~S}: \mathrm{C}, 61.40 ; \mathrm{H}, 3.96 ; \mathrm{N}, 22.03 ; \mathrm{S}$, 12.61. Found: C, 61.13; H, 3.88; N, 21.87; S, 12.52 .

\subsubsection{Reaction of 1 with 4,4-Dimethoxybutan-2-one}

A mixture of benzylidene-malononitrile $1(1.54 \mathrm{~g}, 10.0 \mathrm{mmol})$ with acetylacetaldehyde, dimethyl acetal (AADMA, $10.0 \mathrm{mmol}$ ) in absolute ethanol $(50 \mathrm{~mL})$ was refluxed for $4 \mathrm{~h}$ in the presence of a catalytic amount (10\%wt.) of the catalyst (Method A using Cs beads and Method B using Cs-PVP beads). The solid product, so formed, was filtered off and recrystallized from ethanol.

5-Acetyl-2-amino-4-phenyl-4H-pyran-3-carbonitrile (13). Yellow powder; \% Yields: Method A (Cs beads $=0 \%)$, Method B $(\mathrm{Cs}-\mathrm{PVP}=70 \%) ; 198^{\circ} \mathrm{C}$; IR $(\mathrm{KBr}): \mathrm{v}=1701(\mathrm{C}=\mathrm{O}), 2205(\mathrm{CN}), 3320-3400$ $\left(\mathrm{NH}_{2}\right.$ groups) $\mathrm{cm}^{-1} ;{ }^{1} \mathrm{H}-\mathrm{NMR}\left(\mathrm{DMSO}_{-} \mathrm{d}_{6}\right): \delta=2.32\left(\mathrm{~s}, 3 \mathrm{H}, \mathrm{CH}_{3}\right), 4.29(\mathrm{~s}, 1 \mathrm{H}, \mathrm{C}-2$ pyran$), 6.94(\mathrm{~s}, 2 \mathrm{H}$, $\left.\mathrm{NH}_{2}\right), 7.14-7.33$ (m, 5H, Phenyl); ${ }^{13} \mathrm{C}-\mathrm{NMR}\left(\mathrm{DMSO}_{6}\right)$ : $\delta=19.4\left(\mathrm{CH}_{3}\right), 38.6(\mathrm{C}-4$, pyran), $60.9(\mathrm{C}-3$, 
pyran), 114.2 (C-5, pyran), 116.8 (CN), 122.1, 128.4, 129.0, 138.6, (phenyl), 152.9, 157.3 (C-2, C-6 pyran), $183.9(\mathrm{C}=\mathrm{O})$; MS, $m / z(\%), 240.1\left(\mathrm{M}^{+}, 24\right), 197.1$ (92), 163.1 (100). Anal. Calcd. for $\mathrm{C}_{14} \mathrm{H}_{12} \mathrm{~N}_{2} \mathrm{O}_{2}$ : C, 69.99; H, 5.03; N, 11.66. Found: C, 69.78; H, 4.92; N, 11.49.

\subsubsection{Reaction of Enaminones 14a,b with Malononitrile}

A mixture of $(10.0 \mathrm{mmol})$ of enaminone 14a,b with malononitrile $(0.66 \mathrm{~g}, 10.0 \mathrm{mmol})$, in absolute ethanol $(50 \mathrm{~mL})$ was refluxed for $3 \mathrm{~h}$ in the presence of catalytic amounts $(10 \% \mathrm{wt}$.) of the catalyst (Method A using Cs beads and Method B using Cs-PVP beads). The solid product, so formed, was filtered off and recrystallized from ethanol.

2-Cyano-5-(dimethylamine)-5-phenylpenta-2,4-dienamide (15a). Yellow crystals; \% Yields: Method A $(\mathrm{Cs}$ beads $=80 \%)$, Method B $(\mathrm{Cs}-\mathrm{PVP}=90 \%)$; Mp: $257{ }^{\circ} \mathrm{C} ; \mathrm{IR}\left(\mathrm{KBr}, \mathrm{cm}^{-1}\right): v=1667(\mathrm{CO}), 2191$ $(\mathrm{CN}), 3330$ and $3395\left(\mathrm{NH}_{2}\right) ;{ }^{1} \mathrm{H}-\mathrm{NMR}\left(400 \mathrm{MHz}, \mathrm{DMSO}_{-} \mathrm{d}_{6}\right) \delta=2.77\left(\mathrm{~s}, 3 \mathrm{H}, \mathrm{CH}_{3}\right), 3.16(\mathrm{~s}, 3 \mathrm{H}$, CH3), 5.63 (d, 1H, $J=12.6 \mathrm{~Hz}, \mathrm{H}-4), 6.84$ (s, 2H, NH 2$), 6.98$ (d, 1H, $J=12.6 \mathrm{~Hz}, \mathrm{H}-3), 7.26-7.29$ (m,

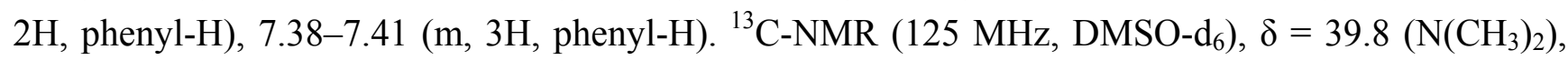
87.6, 96.9, $118.8(\mathrm{CN}), 128.6,129.6,134.0$ (aromatic carbons), 153.3 (C-3), 164.6 (C-5), 165.11 $(\mathrm{C}=\mathrm{O})$. $\mathrm{MS}(\mathrm{m} / \mathrm{z}(\%)): 241.1\left(\mathrm{M}^{+}, 100\right), 179.1(76)$. Anal. Calcd. for $\mathrm{C}_{14} \mathrm{H}_{15} \mathrm{~N}_{3} \mathrm{O}: \mathrm{C}, 69.69 ; \mathrm{H}, 6.27 ; \mathrm{N}$, 17.41. Found: C, 69.56; H, 6.27; N, 17.29.

2-Cyano-5-(dimethylamino)-5-(furan-2-yl)penta-2,4-dienamide (15b). Reddish brown crystals; $\%$ Yields: Method A (Cs beads $=78 \%)$, Method B $(\mathrm{Cs}-\mathrm{PVP}=95 \%)$; M.p. $245^{\circ} \mathrm{C}$; IR $\left(\mathrm{KBr}, \mathrm{cm}^{-1}\right)$ : $v=1669(\mathrm{CO}), 2189(\mathrm{CN}), 3340$ and $3305\left(\mathrm{NH}_{2}\right) ;{ }^{1} \mathrm{H}-\mathrm{NMR}\left(400 \mathrm{MHz}, \mathrm{DMSO}-\mathrm{d}_{6}\right), \delta=2.97(\mathrm{~s}, 6 \mathrm{H}$, $\left.\mathrm{N}\left(\mathrm{CH}_{3}\right)_{2}\right), 5.59(\mathrm{~d}, 1 \mathrm{H}, J=12.5 \mathrm{~Hz}, \mathrm{H}-4), 6.72(\mathrm{~d}, 1 \mathrm{H}, J=5.0 \mathrm{~Hz}$, furyl H-3), $6.78(\mathrm{~d}, 1 \mathrm{H}, J=5.0 \mathrm{~Hz}$, furyl H-5), $7.02\left(\mathrm{~s}, 2 \mathrm{H}, \mathrm{NH}_{2}\right), 7.56(\mathrm{~d}, 1 \mathrm{H}, J=12.5 \mathrm{~Hz}, \mathrm{H}-3), 7.99$ (t, 1H, $J=5.0 \mathrm{~Hz}$, furyl H-4); ${ }^{13} \mathrm{C}-\mathrm{NMR}\left(125 \mathrm{MHz}, \mathrm{DMSO}-\mathrm{d}_{6}\right): \delta=40.77,90.40,98.31,111.53,115.75,118.38,144.80,145.37$, 151.73, 153.40 (C-5), $164.49\left(\mathrm{CONH}_{2}\right)$. MS (m/z (\%)): $231.1\left(\mathrm{M}^{+}, 21\right), 179.1(100)$. Anal. Calcd. for $\mathrm{C}_{12} \mathrm{H}_{13} \mathrm{~N}_{3} \mathrm{O}_{2}$ : C, 62.33; H, 5.67; N, 18.17. Found: C, 62.19; H, 5.57; N, 17.58.

\subsubsection{Oxidation of Methyl Pyridazinone with Cs-PVP-Fe(III) Complex}

Hydrogen peroxide solution (10 mmol, 30\%) was added carefully to a preheated solution of methylpyridazinones 16a,b $(2 \mathrm{mmol})$ in glacial acetic acid $(5 \mathrm{~mL})$. The reaction mixture was then refluxed in the presence of $10 \%$ wt of Cs-PVP/Fe catalyst until thin layer chromatography indicated that the reaction was completed. The solid crude product, so formed, was poured into ice/water mixture $(20 \mathrm{~mL})$ and stirred for $30 \mathrm{~min}$. The product so formed was extracted using $\mathrm{CH}_{2} \mathrm{Cl}_{2}$. The organic layer was dried over anhydrous $\mathrm{Na}_{2} \mathrm{SO}_{4}$ and then concentrated under reduced pressure to yield analytically pure products $\mathbf{1 7 a}, \mathbf{b}$. The used Cs-PVP/Fe(III) catalyst could be regenerated and used for 5 times without appreciable loss of activity.

7-Amino-2-phenylfuro[3,4-d]pyridazin-1(2H)-one (17a). Yellow powder; M.p. $198{ }^{\circ} \mathrm{C}$; IR ( $\left.\mathrm{KBr}, \mathrm{cm}^{-1}\right)$ : $v=1660(\mathrm{CO}), 3330$ and $3390\left(\mathrm{NH}_{2}\right) ;{ }^{1} \mathrm{H}-\mathrm{NMR}\left(400 \mathrm{MHz}, \mathrm{DMSO}-\mathrm{d}_{6}\right), \delta=6.07\left(\mathrm{~s}, 2 \mathrm{H}, \mathrm{NH}_{2}\right), 7.46$ (s, $1 \mathrm{H}$, pyridazinone), 7.51 (m, 5H, phenyl), 8.14 (s, 1H, furan); ${ }^{13} \mathrm{C}-\mathrm{NMR}\left(125 \mathrm{MHz}, \mathrm{DMSO}-\mathrm{d}_{6}\right)$, $\delta=114.1,121.6,126.8,130.7,131.2,139.9,140.8,144.0,147.2$ (aromatic carbons), $168.2(\mathrm{C}=\mathrm{O})$. MS 
(m/z (\%)): $227.1\left(\mathrm{M}^{+}, 12\right), 77.1$ (100). Anal. Calcd. for $\mathrm{C}_{12} \mathrm{H}_{9} \mathrm{~N}_{3} \mathrm{O}_{2}: \mathrm{C}, 63.43 ; \mathrm{H}, 3.99 ; \mathrm{N}, 18.49$. Found: C, 63.28; H, 3.78; N, 18.29.

7-Amino-2-(4-chlorophenyl)furo[3,4-d]pyridazin-1(2H)-one (17b). Pale yellow powder. (M.p. $\left.216{ }^{\circ} \mathrm{C}\right)$; IR $\left(\mathrm{KBr}, \mathrm{cm}^{-1}\right): v=1668(\mathrm{CO}), 3360$ and $3330\left(\mathrm{NH}_{2}\right) ;{ }^{1} \mathrm{H}-\mathrm{NMR}\left(400 \mathrm{MHz}, \mathrm{DMSO}-\mathrm{d}_{6}\right), \delta=6.29$ (s, $2 \mathrm{H}, \mathrm{NH}_{2}$ ), 7.25 (d, 2H, o-H, $J=8 \mathrm{~Hz}$, aryl), 7.69 (d, 2H, m-H, $J=8 \mathrm{~Hz}$, aryl), 8.26 (s, 1H, furan); ${ }^{13} \mathrm{C}-\mathrm{NMR}\left(125 \mathrm{MHz}, \mathrm{DMSO}-\mathrm{d}_{6}\right) \delta=113.1,124.4,126.9,128.6,129.0,133.1,139.1,151.7,155.9$ (aromatic carbons), $171.9(\mathrm{C}=\mathrm{O}) . \mathrm{MS}(\mathrm{m} / \mathrm{z}(\%)$ : $261.1(\mathrm{M}+, 4), 111.1$ (100). HRMS; 261.0298 $\left(\mathrm{C}_{12} \mathrm{H}_{8} \mathrm{O}_{2} \mathrm{~N}_{3} \mathrm{Cl}_{1}\right)$.

\section{Conclusions}

We could clearly show that chitosan-g-PVP beads can be used as an efficient basic, recyclable, environmentally friendly biocatalyst for Michael additions while its supported iron (III) complex is a promising catalyst for controlled oxidation of alkyl functions. The novel catalysts, Cs-PVP and Cs-PVP/Fe(III) beads, could be regenerated and reactivated at least five times, without appreciable loss of activity.

\section{Acknowledgments}

The authors are grateful to the Kuwait University Research Administration for financial support of project SC 01/08, Analytical facilities provided by SAF projects No. GS 01/01, GS 01/03, GS 03/08 \& GS 01/05 are greatly appreciated.

\section{Conflict of Interest}

The authors declare no conflict of interest.

\section{References and Notes}

1. Handbook of Green Chemistry and Technology; Clark, J., Macquarrie, D., Eds.; Blackwell Science Ltd.: Oxford, UK, 2002.

2. Gavrilescu, M.; Chisti, Y. Biotechnology-A sustainable alternative for chemical industry. Biotechnol. Adv. 2005, 23, 471-499.

3. Brundtland, G.H. Our Common Future, World Commission on Environment and Development; Oxford University Press: Oxford, UK, 1987.

4. Kunbeck, D.; Saidulu, G.; Reddy, K.R.; Diaz, D. Critical assessment of the efficiency of chitosan biohydrogel beads as recyclable and heterogeneous organocatalyst for $\mathrm{C}-\mathrm{C}$ bond formation. Green Chem. 2012, 14, 378-392.

5. Bommarius, A.S.; Riebel, B.R. Biocatalysis: Fundamentals and Applications; Wiley-VCH: Weinheim, Germany, 2004; p. 624.

6. Nemtsev, S.V.; Gamzazade, A.I.; Rogozhin, S.V.; Bykova, V.M.; Bykov, V.P. Deacetylation of chitin under homogeneous conditions. Applied Biochem. Microbiol. 2002, 38, 521-526. 
7. Udomchai, C.; Piyabutr, W.; Chuen, H.N.; Willem S.F.; Suwalee, C. Chemical Deacetylation of Shrimp Chitin in different Conditions. Adv. Chitin Sci. 1998, 3, 165-168.

8. Tajik, H.; Moradi, M.; Rohani, S.M.R.; Erfani, A.M.; Jalali, F.S.S. Preparation of Chitosan from Brine Shrimp (Artemia urmiana) Cyst Shells and Effects of Different Chemical Processing Sequences on the Physicochemical and Functional Properties of the Product. Molecules 2008, 13, 1263-1274.

9. Al-Matar, H.M.; Khalil, K.D.; Meier, H.; Kolshorn, H.; Elnagdi, M.H. Chitosan as heterogeneous catalyst in Michael additions: the reaction of cinnamonitriles with active methylene moieties and phenols. ARKIVOC 2008, 16, 288-301.

10. Gomha, S.M.; Riyadh, S.M. Synthesis of triazolo[4,3- $b][1,2,4,5]$ tetrazines and triazolo[3,4- $b]$ $[1,3,4]$ thiadiazines using chitosan as ecofriendly catalyst under microwave irradiation. ARKIVOC 2009, 11, 58-68.

11. Khalil, K.D.; Al-Matar, H.M.; Elnagdi, M.H. Chitosan as an eco-friendly heterogeneous catalyst for Michael type addition reactions. A simple and efficient route to pyridones and phthalazines. Eur. J. Chem. 2010, 1, 252-258.

12. Hardy, J.E.; Hubert, S.; Macquarrie, D.J.; Wilson, A.J. Chitosan-based heterogeneous catalysts for Suzuki and Heck reactions. Green Chem. 2004, 6, 53-56.

13. Elnagdi, M.H.; Abed, N.M.; Elmoghayar, M.R.H.; Fleta, D.H. Reactivity of $\alpha$-cyanochelkones as Michael acceptor. Indian J. Chem. 1976, 14B (6), 422-424.

14. Abdou, S.; Fahmy, S.M.; Sadek, K.U.; Elnagdi, M.H. Activated nitriles in heterocyclic synthesis: A novel synthesis of pyrano[2,3-c]pyrazoles. Heterocycles 1981, 16, 2177-2180.

15. Elnagdi, M.H.; Maksoud, F.A.; Abdel-Aal, F.A.; Hafez, E.A.; Yassin, Y.M. Studies on alkyl heterocyclic aromatic compounds. New route for synthesis of Polyazana-phthalenes. Z. Naturforsch. 1989, 44B (6), 683-689.

16. Elagamey, A.A.; El-Taweel, F.M.A.; Sowellim, S.Z.; Sofan, M.A.; Elnagdi, M.H. Nitriles in heterocyclic synthesis: A novel route for the synthesis of naphthalopyrans, pyridines $2 \mathrm{H}-$ and 4H-pyrans. Collect. Czech. Chem. Commun. 1990, 55, 524-534.

17. Elnagdi, M.H.; Ghozlan, S.A.S.; Abdelhamid, I.A. Alkyl-substituted heteroaromatics as precursors to polycyclic heteroaromatics: recent developments. ARKIVOC 2008, 10, 54-84.

18. Fu, C.; Hung, T.; Su, C.; Suryani, D.; Wu, W.; Dai, W.; Yeh, Y. Immobilization of calcium oxide onto chitosan beads as a heterogeneous catalyst for biodiesel production. Polym. Int. 2011, 60, 957-962.

19. Shamim, T.; Paul, S. Silica Functionalized $\mathrm{Cu}(\mathrm{I})$ as a Green and Recyclable Heterogeneous Catalyst for the Huisgen 1,3-Dipolar Cycloaddition in Water at Room Temperature. Catal. Lett. 2010, 136, 260-265.

20. Ricci, A.; Bernardi, L.; Gioia, C.; Vierucci, S.; Robitzer, M.; Quignard, F. Chitosan aerogel: a recyclable, heterogeneous organocatalyst for the asymmetric direct aldol reaction in water. Chem. Commun. 2010, 46, 6288-6290.

21. Qin, Y.; Zhao, W.; Yang, L.; Zhang, X.; Cui, Y. Chitosan-based heterogeneous catalysts for enantioselective Michael reaction. Chirality 2012, 24, 640-645. 
22. Dekamin, M.G.; Azimoshan, M.; Ramezani, L. Chitosan: A Highly Efficient Renewable and Recoverable Bio-Polymer Catalyst for Expeditious Synthesis of $\alpha$-Amino nitriles and Imines under Mild Conditions. Green Chem. 2013, in press.

23. Watile, R.A.; Bhanage, B.M. Chitosan biohydrogel beads: A recyclable, biodegradable, heterogeneous catalyst for the regioselective synthesis of 5-aryl-2-oxazolidinones from carbon dioxides and aziridines at mild conditions. Ind. J. Chem. 2012, 51A, 1354-1360.

24. Yuanchen, C.; Hefeng, Z.; Runtao, L.; Yi, L.; Chu, X. Asymmetric Henry reaction catalyzed by chitosan and its L-proline derivatives. Chin. J. Org. Chem. 2010, 30, 707-712.

25. Chtchigrovsky, M.; Primo, A.; Gonzalez, P.; Molvinger, K.; Robitzer, M.; Quignard, F.; Taran, F. Functionalized chitosan as a green, recyclable, biopolymer-supported catalyst for the $(3+2)$ Huisgen cycloaddition. Angrew. Chem. 2009, 48, 5916-5920.

26. Elkholy, S.S.; Khalil, K.D.; Elsabee, M.Z. Homogeneous and heterogeneous grafting of 4-vinylpyridine onto chitosan. J. Appl. Poly. Sci. 2006, 99, 3308-3317.

27. Barriiro-Iglesias, R.; Coronilla, R.; Concheiro, A.; Alvarez-Lorenzo, C. Preparation of chitosan beads by simultaneous cross-linking/insolubilisation in basic $\mathrm{pH}$. Rheological optimisation and drug loading/release behavior. Euro. J. Pharm. Sci. 2005, 24, 77-84.

28. Guibal, E. Heterogeneous catalysis on chitosan-based materials: a review. Prog. Polym. Sci. 2005, 30, 71-109.

29. Guibal, E.; Milot, C.; Tobin, J.M. Palladium sorption using chitosan derivatives. Ind. Eng. Chem. Res. 1998, 37, 1454-1463.

30. Wan Ngah, W.S.; Endud, C.S.; Mayanar, R. Removal of copper(II) ions from aqueous solution onto chitosan and crosslinked chitosan beads. React. Funct. Polym. 2002, 50, 181-190.

31. Yang, T.C.; Zall, R.R. Adsorption of metals by natural polymers generated from sea food processing wastes. Ind. Eng. Chem. Prod. Res. Dev. 1984, 23, 168.

32. Varma, A.J.; Deshpande, S.V.; Kennedy, J.F. Metal complexation by chitosan and its derivatives: a review. Carbohydr. Polym. 2004, 55, 77-93.

33. Wan Ngah, W.S.; Ghani, S.Ab.; Kamari, A. Adsorption behaviour of Fe(II) and Fe(III) ions in aqueous solution on chitosan and cross-linked chitosan beads. Bioresour. Technol. 2004, 96, 443-450.

34. Burke, A.; Yilmaz, E.; Hasirci, N. Evaluation of Chitosan as a Potential Medical Iron (III) Ion Adsorbent. Turk. J. Med. Sci. 2000, 30, 341-348.

35. Crystallographic data for the structures of compounds $\mathbf{2}$, and $\mathbf{4}$ reported in this paper have been deposited with the Cambridge Crystallographic Data Centre as supplementary publications Nos. 895828 and 895829 . These data can be obtained free of charge from the Cambridge Crystallographic Data Centre. Available online: http://www.ccdc.cam.ac.uk (accessed on 6 May 2013).

36. Elnagdi, N.M.H.; Al-Hokbany, N.S. Organocatalysis in Synthesis: L-Proline as an Enantioselective Catalyst in the Synthesis of Pyrans and Thiopyrans. Molecules 2012, 17, 4300-4312.

37. Alnajjar, A.; Abdelkhalik, M.M.; Al-Enezi, A.; Elnagdi, M.H. Enaminones as Building Blocks in Heterocyclic Syntheses: Reinvestigating the Product Structures of Enaminones with Malononitrile. A Novel Route to 6-Substituted-3-Oxo-2,3-Dihydropyridazine-4-Carboxylic Acids. Molecules 2009, 14, 68-77. 
38. Al-Matar, H.M.; Khalil, K.D.; Al-Kanderi, M.F.; Elnagdi, M.H. Studies on 3-oxoalkanenitriles: novel rearrangement reactions observed in studies of the chemistry of 3-heteroaroyl-3oxoalkanenitriles as novel routes to 2-dialkylaminopyridines. Molecules 2012, 17, 897-909.

39. Tomczak, E. Application of ANN and EA for description of metal ions sorption on chitosan foamed structure-Equilibrium and dynamics of packed column. Comp. Chem. Eng. 2011, 35, 226-235.

40. Kaupp, G.; Naimi-Jamal, M.R.; Schmeyers, J. Uncatalysed Knoevenagel condensation in aqueous medium at room temperature. Tetrahedron 2003, 59, 3753-3760.

41. Babu, N.S.; Pasha, N.; Venkateswara-Rao, K.T.; Sai-Prasad, P.S.; Lingaiah, N. A heterogeneous strong basic $\mathrm{Mg} / \mathrm{La}$ mixed oxide catalyst for efficient synthesis of polyfunctionalized pyrans. Tetrahedron Lett. 2008, 49, 2730-2733.

42. Elagami, A.A.; Sewilam, S.Z.; El-Taweel, F.M.A.; Elnagdi, M.H. Nitriles in heterocyclic synthesis: Novel synthesis of benzo[b]pyrans naphtho[1,2-b]pyrano, naphtho[2,1-b]pyrans, pyrano[3,2-b]quinolines and pyrano[3,2-c] quinolines. Collect. Czech. Chem. Commun. 1988, 53, 1534.

Sample Availability: Samples of the compounds $\mathbf{2 , 3}, \mathbf{4}, \mathbf{7}, \mathbf{1 1}, \mathbf{1 5 a} \mathbf{a}, \mathbf{b}, \mathbf{1 7 a}, \mathbf{b}$. are available from the authors.

(C) 2013 by the authors; licensee MDPI, Basel, Switzerland. This article is an open access article distributed under the terms and conditions of the Creative Commons Attribution license (http://creativecommons.org/licenses/by/3.0/). 